\title{
Primary total knee replacement for tibial plateau fractures in older patients: a systematic review of 197 patients
}

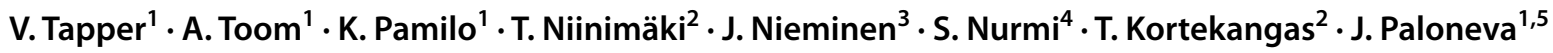

Received: 26 February 2021 / Accepted: 24 August 2021 / Published online: 31 August 2021

(c) The Author(s) 2021

\begin{abstract}
Introduction Tibial plateau fractures are typically treated with osteosynthesis. In older patients, osteosynthesis is associated with some complications, risk of post-traumatic osteoarthritis and long partial, or non-weight bearing during the recovery phase. To avoid these problems, primary total knee replacement (TKR) has become an increasingly common treatment option. The aim of this study was to evaluate all the relevant literature and summarize the current evidence-based knowledge on the treatment of tibial plateau fractures with primary TKR in older patients.

Materials and methods A systematic literature search of studies on total knee replacement (TKR) as primary treatment for acute traumatic tibial plateau fracture was conducted using OVID Medline, Scopus, and Cochrane databases from 1946 to 18 November 2019. We included all studies without restrictions regarding total knee replacement (TKR) as primary treatment for acute traumatic tibial plateau fracture.

Results Of the 640 reviewed articles, 16 studies with a total of 197 patients met the inclusion criteria. No controlled trials were available, and the overall quality of the literature was low. The results, using different clinical scoring systems, were good or fair. Four-year follow-up complication $(6.1 \%)$ and revision (3.6\%) rates after primary TKR appeared to be lower than after secondary TKR (complication rate $20-48 \%$, revision rate $8-20 \%$ ) but higher than after elective primary TKR.

Conclusion Based on low-quality evidence, TKR appears to be a useful treatment option for tibial plateau fractures in older patients. Controlled trials are mandatory to determine the relative superiority of these two options as primary treatment of tibial plateau fractures in older patients.
\end{abstract}

Keywords Surgery $\cdot$ Knee $\cdot$ Tibial plateau fracture $\cdot$ Total knee replacement $\cdot$ Primary total knee replacement . Osteosynthesis

\section{Introduction}

For many years, arthroplasty has been the gold standard treatment for femoral neck fractures in older patients. More recently, arthroplasty has also become a significant primary treatment option for complex elbow and shoulder fractures [1,2]. It has been assumed that peri-articular

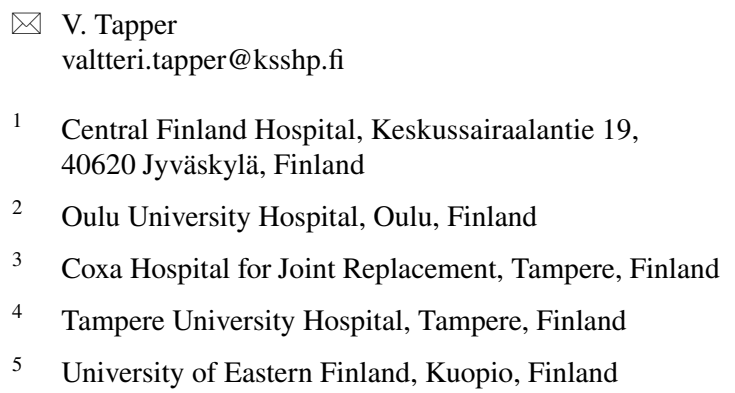

fractures around the knee can be similarly treated, especially in patients with osteoporosis and with fractures that are difficult to reconstruct or may lead to rapid progression of posttraumatic osteoarthritis.

Proximal tibia fractures are relatively common in the older population, but demanding to treat. Tibial plateau fractures, in turn, have been associated with higher mortality [3]. The incidence of tibial plateau fractures rises with age, and the majority of patients are women $[4,5]$. Of all intra-articular proximal tibia fractures, $24 \%$ occur in older persons and account for $8 \%$ of all fractures in patients over age 65 years [6]. The incidence of tibial plateau fractures will increase in the future [6-8].

Conflicting results have been reported for open reduction and internal fixation (ORIF) of tibial plateau fractures in older people. Some studies have found a high risk of complications, such as infections, loss of reduction, 
malalignment, delayed union or nonunion, and risk for the development of post-traumatic osteoarthritis (OA) [6, 9-15]. However, many other studies have reported ORIF to have good outcomes in older people [8, 16-20].

In view of the above-mentioned complications, primary total knee replacement (TKR) is an under-reported treatment option. It could be a feasible first-line treatment, especially in fragile older patients [21-25]. Here we present a systematic review of all the relevant literature and summarize the current evidence-based knowledge on the treatment of tibial plateau fractures with primary TKR in older people.

\section{Materials and methods}

We conducted a systematic search following the Preferred Reporting Items for Systematic Reviews and Meta-analyses (PRISMA) using a Prisma checklist. The review was registered with PROSPERO (CRD42020102352).

\section{Literature search}

The literature search was conducted in three electronic databases (OVID Medline, Scopus, and Cochrane). The search covered the years 1946-2019, with the last search for 18.11.2019. The search strategy was developed by an experienced informatician, using the text words"knee joint replacement", "knee TEP”, "total knee arthroplasty", "knee arthroplasty" and "tibial head fractures", "proximal tibia* fractur*","tibial plateau fracture*", "proximal tibia* fracture", "tibial plateau fracture", "knee joint fractures"," tibial fractures not femoral fractures". The MESH terms are detailed in the electronic supplementary material. The study selection flowchart is presented in Fig. 1.

\section{Inclusion and exclusion criteria}

All English, German, and French studies on TKR as primary treatment for acute tibial plateau fracture were included. The inclusion criteria for this review were based on the PICOS framework (see Table 1).
Fig. 1 Flowchart of study selection
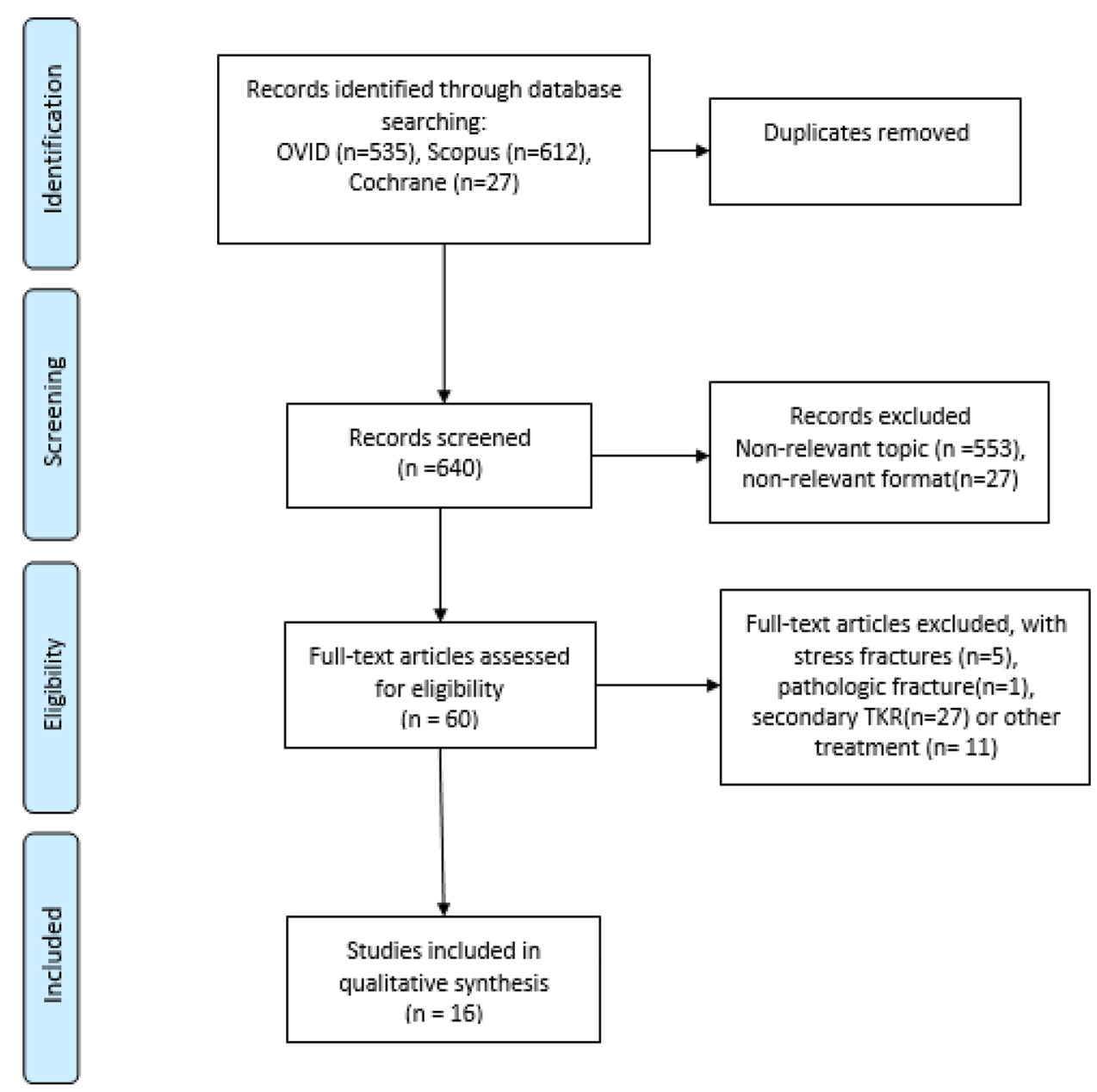
Table 1 PICOS

\begin{tabular}{ll}
\hline Population & Patients with acute traumatic tibial plateau fracture \\
Intervention & Primary total knee replacement \\
Comparison & Any other treatment \\
Outcome & Any outcome \\
Studies & $\begin{array}{c}\text { All studies excluding conference abstracts, book } \\
\text { chapters, reviews etc }\end{array}$ \\
\hline
\end{tabular}

Studies of osteosynthesis, external fixator, or any other treatment were excluded, as were studies on stress fractures, intra-operative fractures, pathologic fractures, and tibial fractures treated with secondary TKR. Conference abstracts, book chapters, and reviews were also excluded from our search.

\section{Data screening and extraction}

The database search yielded 640 abstracts after removal of duplications. To exclude irrelevant records, conference abstracts, reviews, and expert opinions, two authors (AT, VT) performed title and abstract screening independently. The full-text selections from the remaining 55 articles were subsequently performed by the same two authors independently. Discrepancies were resolved through discussion.

Five of the selected studies concerned peri-articular knee fractures treated with primary TKR. Patients in these studies were excluded if cases with distal femoral fractures or extraarticular tibial fractures could not be separated from cases with tibial plateau fractures [24, 26-29]. Subject parameters were excluded where data were unreported or unclear.

\section{Outcome measures}

Study and subject parameters were collected by the same author (VT). The collected parameters included year of publication, quality of evidence, length of follow-up, sex, age, complications, reoperations, fracture type, the type of prosthesis used, and surgical outcomes measured by the following clinical scoring systems: Oxford Knee Score (OKS; range 12-60 points) [30], Knee Society Score (KSS; range 0-200 points) [31], Tegner Activity Scale (Range 0-10) [32] and Parker Mobility Score(Range 0-9) [33]. In all the above, a higher score indicates better knee function. Clinical scores were recorded at the last follow-up visit. Four superficial infections, three hematomas and one other wound-related problem were excluded owing to insufficient documentation. Deep infections were defined as infections requiring surgical revision. All other complications (deep infection, intra-operative fracture, periprosthetic fracture, prosthetic loosening, deep vein thrombosis (DVT), knee stiffness requiring revision) reported in the original articles were recorded.

\section{Statistical analysis}

A meta-analysis of case series was not possible owing to the diversity of outcomes measures, unclear data, and a low event rate. Comparison of main outcomes by fracture classification and by complications between the prosthetic models used were quantitatively analyzed with the SPSS data analysis program, and $p$ value $<0.05$ was considered statistically significant. Descriptive results of the included studies are expressed as absolute numbers with percentages, mean values, and standard deviations.

\section{Results}

Sixteen series on 197 patients met the inclusion criteria. No prospective controlled trials were found. The included studies are presented in Tables 2 and 3.

Mean patient age ranged between 68 and 86 (SD 6.3) years [16, 21-27, 29, 34-37].

Mean follow-up time ranged from 2 months to 4 years (mean 28 months, SD 13 months) [12, 16, 21-27, 34-37]. Studies using the AO classification identified seven A-type (1\%), $70 \mathrm{~B}$-type (65\%) and $31 \mathrm{C}$-type (39\%) tibia fractures in a total of 108 patients [21, 23, 25-27, 29, 34, 37]. The six series using Schatzker's tibia fracture classification [12, 22, 24, 35, 36, 38] identified 28 II-type (39\%), 15 III-type (21\%), 14 IV-type (20\%), 11 V-type (15\%), and three VI-type (4\%) fractures in 71 patients.

The OKS score was 29.5 and 35.7 points in 24 patients [24, 35]. Reported KSS scores ranged from 127 to 170 points (140 patients), function scores from 43 to 84 points and knee scores from 78 to 90.7 points (87 patients) [12, 21, 23-25, 34-36]. The mean global KSS score was 153 (SD 15) points. The mean KSS score was 150 (SD 43) points in patients with B-type fractures $(\mathrm{N}=26)$ and $144(\mathrm{SD} 38)$ points in patients with a bicondylar C-type fracture $(\mathrm{N}=14)$. In the remaining cases, fracture type was not reported. The difference between B and C-type fractures was not statistically significant $(p=0.709)$. Maximum flexion was $98-116$ degrees in 101 patients [11, 19-21, 27, 33-37]. In the reviewed studies, mean maximum flexion was 108 (SD 7) degrees, in patients with B-type fractures (27 patients) 110 (SD 13) degrees, and in patients with bicondylar C-type fracture (14 patients) 109 (SD 15) degrees ( $\mathrm{p}=0.738$ between groups). No statistically significant difference between fracture groups was found. In the remaining cases, fracture type was not reported. Complications were reported in 12 studies (infection, periprosthetic fracture, loosening, stiffness, thromboembolism) [12, $21-23,25,26,28,29,34-37]$. Ten complications $(6.1 \%)$ and six $(3.6 \%)$ revisions were reported in 163 patients during variable follow-up between studies (see Table 3). Despite conversion of the Schatzker classified fractures to the AO 
Table 2 Studies included in the review

\begin{tabular}{llllll}
\hline Publisher & Country & Year & $\begin{array}{l}\text { Level of } \\
\text { evidence }\end{array}$ & Patients & $\begin{array}{l}\text { Mean } \\
\text { follow-up time } \\
\text { (months) }\end{array}$ \\
\hline Kilian et al. [37] & Germany & 2003 & IV & 2 & 2 \\
Nau et al. [26] & Austria & 2003 & IV & 3 & Unclear data \\
Nourissat et al. [12] & France & 2006 & IV & 4 & 42 \\
Schwarz et al. [34] & Austria & 2008 & IV & 9 & 16 \\
Vermeire et al. [21] & Belgium & 2010 & IV & 12 & 31 \\
Malviya et al. [27] & UK & 2011 & IV & 15 & 39 \\
Kini et al. [38] & Singapore & 2013 & IV & 6 & Unclear data \\
Boureau et al. [24] & France & 2015 & III & 11 & 31 \\
Haufe et al. [25] & Germany & 2016 & IV & 30 & 19 \\
Shimizu et al. [16] & Japan & 2016 & IV & 2 & 27 \\
Sarzaeem et al. [23] & Iran & 2017 & III & 30 & 48 \\
Huang et al. [22] & China & 2017 & IV & 6 & 36 \\
Ebied et. al. [28] & Egypt & 2018 & IV & 18 & 32 \\
Abdelbadie et al. [36] & Egypt & 2019 & III & 22 & 27 \\
Tapper et al. [35] & Finland & 2019 & IV & 22 & 19 \\
Pasurka et al. [29] & Germany & 2019 & III & 5 & Unclear data \\
\hline
\end{tabular}

classification, the event rate was too low for further comparison between complications and fracture classification.

Prostheses were categorized by stability into three types: hinge, total stabilized, and surfacing prostheses (cruciate retaining or posterior stabilized). The prosthesis used was reported in $144(75 \%)$ patients [21, 23, 24, 27, 35-37]: 46 (32\%) were hinged, 32 (22\%) total stabilized, and 66 (46\%) surfacing prostheses.

\section{Discussion}

The overall quality of the literature was low. Based on the limited evidence in the reviewed studies, TKR appears to be a useful treatment option for tibial plateau fractures in older patients with acceptable complication risk. However, according to the results of this review study, the choice between ORIF and TKR cannot be made based on the currently available literature.

Many different scoring systems were used to report the outcome of primary TKR for acute tibial plateau fractures in the reviewed studies. The scores showed a good to fair outcome in the majority of cases after a mean follow-up of 28 months. The complication rate after primary TKR appears to be lower than after secondary TKR but higher than after elective primary TKR, and the revision rate followed the same pattern. $[9,39,40]$ These results suggest that primary TKR is a potentially useful choice in future cases, as it would enable minimal use of secondary TKR with its higher complication rate.
Unfortunately, the distribution of fracture types and the prosthetic models used were reported in relation to outcome or complications in only seven of the reviewed studies. Due to the variety of outcome measures, unclear data, and a low event rate, comparison of main outcomes by fracture classification was only possible with the maximum flexion and KSS scores. The difference found was not statistically significant. For the same reasons, comparison of the results and of complications between the prosthetic models used was also not possible.

Furthermore, patient morbidity was reported only in one study (ASA classification) and thus was not included in this review [24]. While no life-threatening complications related to primary TKR operation were reported in the reviewed studies, more studies comparing mortality between primary TKR and ORIF treatment are needed.

Only two studies included a (small) control group treated with ORIF. Abdelbadie et al. reported better range of motion and functional scores in TKR than ORIF patients. Pasurka et al. reported that patients with primary TKR achieved independent mobility earlier than patients treated with ORIF [29]. In both studies, complication and reoperation rates were also lower in the primary TKR group [29, 36].

A major weakness of the data was that only two studies compared the postoperative outcome to the pre-fracture situation [23, 24]. Thus, achieving the main goal, both functional rehabilitation and maintenance of autonomy after TKR, remains controversial [23, 24] 


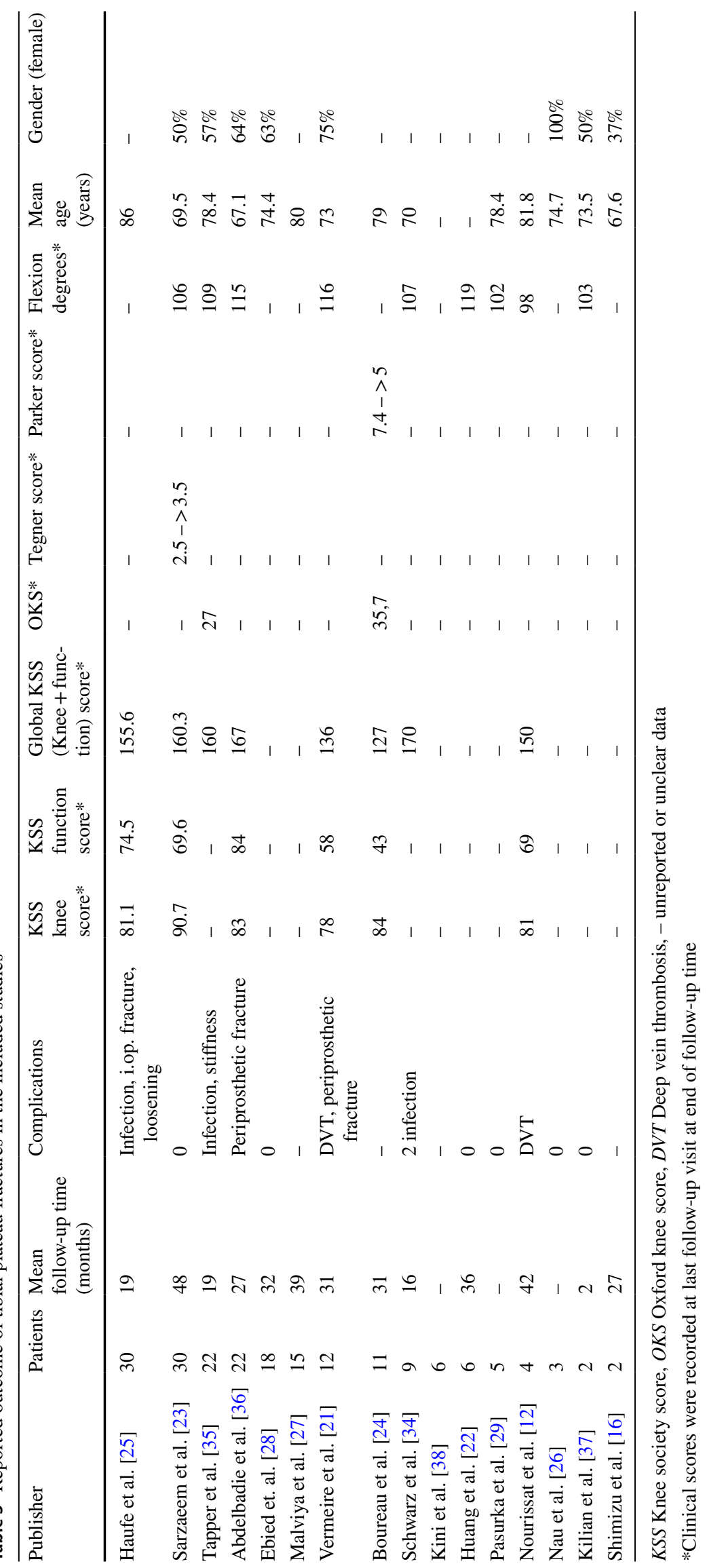




\section{ORIF}

With ORIF, the goals are to achieve anatomical reduction, joint reconstruction, and high stability to allow early weight-bearing. However, to acceptably reduce the joint surface, achieve knee stability and restore the mechanical axis can be challenging due to possible complexity of the fracture or inferior bone quality. ORIF has shown good results in some studies, with low rates $(0-9.5 \%)$ of complications in older patients $[8,9,13,16,17,19]$. However, some problems seem to be associated specifically with tibial plateau fractures treated using ORIF. Postoperative complications of ORIF include deep infection (16\%), malalignment, loss of reduction (30-79\%), and delayed union or nonunion $[6,10,18,41-44]$. Moreover, the risk of complications has been reported to rise with age [10, $17,18,41]$.

The postoperative management of ORIF may be challenging. In most cases, to achieve fracture union in older patients with poor bone quality, a relatively long period of non- or partial weight bearing is warranted. Such immobilization leads to loss of muscle strength, joint contractures, increased risk of venous thromboembolism, bed sores, and prolonged hospital stay [45-47].

Even if adequate reduction and stable fixation are achieved, $21-75 \%$ of patients with intra-articular knee fractures develop post-traumatic OA [13-15]. In comparison to the normal population, these patients are at a 5.3fold risk for post-traumatic osteoarthritis [11]. However, the rates reported for secondary total knee arthroplasty are relatively low. End-stage osteoarthritis leading to secondary total knee arthroplasty typically develops in $4-7.5 \%$ of patients after a median of 3.7-4.6 years post-trauma, and the risk of end-stage osteoarthritis rises with age [11, $48,49]$.

\section{TKR}

Secondary arthroplasty may be considered in cases of failure or poor results after primary ORIF; however, it may be technically challenging owing to distorted anatomy, scarring and internal fixation materials [39, 50]. Moreover, achieving the correct ligamentous balance and patellar tracking, and restoring axial alignment are demanding [51]. The risk of revision surgery after secondary TKR varies from 8 to $20 \%$ in follow-ups lasting up to 11 years $[9,39,40,52]$ and the risk is $1.2-2.4$ times higher than after primary OA $[53,54]$. After 5 years, it seems that no significant differences in revision risk remained between these two groups [54]. Moreover, the complication rate of secondary TKR is as high as $24-48 \%$ in follow-ups lasting up to 6.2 years $[9,39,52]$. The infection risk is 2.9 -fold higher in cases of post-traumatic arthritis compared to TKR performed due to primary osteoarthritis [55].

The majority of the reviewed studies concluded that primary TKR for tibial plateau fracture is a potential treatment option in well-selected patients. Primary TKR is probably a useful primary treatment option in older patients, especially in cases where (1) the patient is a likely candidate for TKR in the near future due to severe pre-existing OA of the knee, when even successful ORIF treatment of a fracture may result in a stiff and painful knee [56]; (2) the fracture is combined with marked bone loss/defects that are difficult to repair or reconstruct; and (3) patient compliance with partial weight-bearing is insufficient and thus ORIF would lead to immobilization.

The advantages of primary TKR are early mobilization, faster rehabilitation, and an assumed decrease in reoperations, achieved through avoiding complications such as malalignment, loss of reduction, and secondary osteoarthritis after ORIF. The weaknesses of primary TKR are the more demanding treatment required in cases of infection and the limited possibilities for revision in cases of complications due to a voluminous prosthesis. However, the implant should survive for the rest of the patient's life, and hence is preferred for older patients.

\section{Limitations of the study}

The quality of the reviewed literature was low (grade 3-4). Moreover, no studies included controlled trials: most were case reports with only a small number of patients.

\section{Conclusion}

No conclusions on the relative superiority of TKR or ORIF as treatment for tibial plateau fractures can be drawn, owing to the low quality of the literature and lack of studies with control groups. To obtain more precise guidelines for such treatment, we need controlled studies that assess the functionality of TKR and ORIF in addition to fracture healing, patient satisfaction and health-related quality of life.

Supplementary Information The online version contains supplementary material available at https://doi.org/10.1007/s00402-021-04150-1.

Acknowledgements The authors would like to thank Aila Ruokokoski for help with the systematic literature search.

Author contributions Study design: VT, AT, JP, and KP. Data collection: VT and AT. Data analysis: VT, AT, and JP. Manuscript preparation VT, AT, JP, KP, TN, JN, TK, and SN. 
Funding Open access funding provided by University of Eastern Finland (UEF) including Kuopio University Hospital. Päivikki and Sakari Sohlberg Foundation.

\section{Declarations}

Conflict of interest None declared.

Ethical approval Not needed for this systematic review.

Open Access This article is licensed under a Creative Commons Attribution 4.0 International License, which permits use, sharing, adaptation, distribution and reproduction in any medium or format, as long as you give appropriate credit to the original author(s) and the source, provide a link to the Creative Commons licence, and indicate if changes were made. The images or other third party material in this article are included in the article's Creative Commons licence, unless indicated otherwise in a credit line to the material. If material is not included in the article's Creative Commons licence and your intended use is not permitted by statutory regulation or exceeds the permitted use, you will need to obtain permission directly from the copyright holder. To view a copy of this licence, visit http://creativecommons.org/licenses/by/4.0/.

\section{References}

1. Ray PS, Kakarlapudi K, Rajsekhar C, Bhamra MS (2000) Total elbow arthroplasty as primary treatment for distal humeral fractures in elderly patients. Injury 31:687-692

2. Mata-Fink A, Meinke M, Jones C et al (2013) Reverse shoulder arthroplasty for treatment of proximal humeral fractures in older adults: a systematic review. J Shoulder Elb Surg 22:1737-1748. https://doi.org/10.1016/j.jse.2013.08.021

3. Elsoe R, Larsen P (2020) Tibial plateau fractures are associated with a long-term increased risk of mortality: a matched cohort study of 7950 patients. Arch Orthop Trauma Surg 140:1705-1711. https://doi.org/10.1007/s00402-020-03408-4

4. Court-Brown CM, McQueen MM (2016) Fractures in the elderly. J. Bone Jt. Surg. - Am. Vol. 98:e36

5. Somersalo A, Paloneva J, Kautiainen $H$ et al (2014) Incidence of fractures requiring inpatient care. Acta Orthop 85:525-530. https://doi.org/10.3109/17453674.2014.908340

6. Frattini M, Vaienti E, Soncini G, Pogliacomi F (2009) Tibial plateau fractures in elderly patients. Musculoskelet Surg 93:109-114. https://doi.org/10.1007/s12306-009-0038-y

7. Gerich T, Bosch U, Schmidt E et al (2001) Knee joint prosthesis implantation after fractures of the head of the tibia. Intermediate term results of a cohort analysis. Unfallchirurg 104:414-419

8. Su EP, Westrich GH, Rana AJ, et al (2004) Operative treatment of tibial plateau fractures in patients older than 55 years. Clin Orthop Relat Res 240-8

9. Weiss NG, Parvizi J, Trousdale RT et al (2003) Total knee arthroplasty in patients with a prior fracture of the tibial plateau. J Bone Jt Surg - Ser A 85:218-221. https://doi.org/10.2106/00004623200302000-00006

10. Ali AM, El-Shafie M, Willett KM (2002) Failure of fixation of tibial plateau fractures. J Orthop Trauma 16:323-329

11. Wasserstein D, Henry P, Paterson JM et al (2014) Risk of total knee arthroplasty after operatively treated tibial plateau fracture a matched-population-based cohort study. J Bone Jt Surg - Ser A 96:144-150. https://doi.org/10.2106/JBJS.L.01691
12. Nourissat G, Hoffman E, Hémon C et al (2006) Total knee arthroplasty for recent severe fracture of the proximal tibial epiphysis in the elderly subject. Rev Chir Orthop Reparatrice Appar Mot 92:242-247

13. Rademakers MV, Kerkhoffs GMMJ, Sierevelt IN et al (2007) Operative Treatment of 109 Tibial Plateau Fractures: Five- to 27-Year Follow-up Results. J Orthop Trauma 21:5-10. https:// doi.org/10.1097/BOT.0b013e31802c5b51

14. Schenker ML, Mauck RL, Ahn J, Mehta S (2014) Pathogenesis and Prevention of Posttraumatic Osteoarthritis After Intra-articular Fracture. J Am Acad Orthop Surg 22:20-28. https://doi.org/ 10.5435/JAAOS-22-01-20

15. Honkonen SE (1995) Degenerative arthritis after tibial plateau fractures. J Orthop Trauma 9:273-277

16. Shimizu T, Sawaguchi T, Sakagoshi D et al (2016) Geriatric tibial plateau fractures: Clinical features and surgical outcomes. J Orthop Sci 21:68-73. https://doi.org/10.1016/j.jos.2015.09.008

17. Roerdink WH, Oskam J, Vierhout PA (2001) Arthroscopically assisted osteosynthesis of tibial plateau fractures in patients older than 55 years. Arthroscopy 17:826-831

18. Parkkinen M, Madanat R, Lindahl J, Mäkinen TJ (2016) Risk Factors for Deep Infection Following Plate Fixation of Proximal Tibial Fractures. J Bone Jt Surg 98:1292-1297. https://doi.org/ 10.2106/JBJS.15.00894

19. Oladeji LO, Worley JR, Crist BD (2019) Age-Related Variances in Patients with Tibial Plateau Fractures. J Knee Surg. https:// doi.org/10.1055/s-0039-1683893

20. Kim JK, Hwang KT, Soh HS et al (2021) Comparison of tibial plateau fracture surgical outcomes between young and elderly patients: are outcomes really poorer in the elderly? Arch Orthop Trauma Surg. https://doi.org/10.1007/s00402-021-03855-7

21. Vermeire J, Scheerlinck T (2010) Early primary total knee replacement for complex proximal tibia fractures in elderly and osteoarthritic patients. Acta Orthop Belg 76:785-793

22. Huang J-F, Shen J-J, Chen J-J, Tong P-J (2016) Primary total knee arthroplasty for elderly complex tibial plateau fractures. Acta Orthop Traumatol Turc 50:702-705. https://doi.org/10. 1016/j.aott.2015.03.001

23. Sarzaeem MM, Omidian MM, Kazemian G, Manafi A (2017) Acute Primary Total Knee Arthroplasty for Proximal Tibial Fractures in Elderly. Arch bone Jt Surg 5:302-307

24. Boureau F, Benad K, Putman S et al (2015) Does primary total knee arthroplasty for acute knee joint fracture maintain autonomy in the elderly? A retrospective study of 21 cases. Orthop Traumatol Surg Res 101:947-951. https://doi.org/10.1016/j.otsr. 2015.09.021

25. Haufe T, Förch S, Müller P et al (2016) The Role of a Primary Arthroplasty in the Treatment of Proximal Tibia Fractures in Orthogeriatric Patients. Biomed Res Int. https://doi.org/10. 1155/2016/6047876

26. Nau T, Pflegerl E, Erhart J, Vecsei V (2003) Primary total knee arthroplasty for periarticular fractures. J Arthroplasty 18:968-971

27. Malviya A, Reed MR, Partington PF (2011) Acute primary total knee arthroplasty for peri-articular knee fractures in patients over 65 years of age. Injury 42:1368-1371. https://doi.org/10.1016/j. injury.2011.06.198

28. Ebied A, Zayda A, Marei S, Elsayed H (2018) Medium term results of total knee arthroplasty as a primary treatment for knee fractures. SICOT-J 4:6. https://doi.org/10.1051/sicotj/2017060

29. Pasurka M, Krinner S, Gelse K (2019) Osteosynthesis or arthroplasty of fractures near the knee joint in geriatric patients - a clinical-economical comparison. Z Orthop Unfall. https://doi.org/ 10.1055/a-0977-3607

30. Dawson J, Fitzpatrick R, Murray D, Carr A (1998) Questionnaire on the perceptions of patients about total knee replacement. J 
Bone Joint Surg Br 80:63-69. https://doi.org/10.1302/0301-620x. 80b1.7859

31. Insall JN, Dorr LD, Scott RD, Scott WN (1989) Rationale of the Knee Society clinical rating system. Clin Orthop Relat Res 13-4

32. Tegner YLJ (1985) Rating systems in the evaluation of knee ligament injuries. - PubMed - NCBI. Clin Orthop Relat Res 198:43-49

33. Parker MJ, Palmer CR (1993) A new mobility score for predicting mortality after hip fracture. J Bone Joint Surg Br 75:797-798

34. Schwarz N, Buchinger W, Mähring M et al (2008) Trauma hospital. Knee arthroplasty as primary therapy for proximal tibial fracture. Unfallchirurg 111:928-932. https://doi.org/10.1007/ s00113-008-1426-8

35. Tapper V, Toom A, Pesola M et al (2019) Knee joint replacement as primary treatment for proximal tibial fractures: analysis of clinical results of twenty-two patients with mean follow-up of nineteen months. Int Orthop. https://doi.org/10.1007/s00264-019-04415-w

36. Abdelbadie A, El-Hennawy A, Sallam A (2019) Primary Total knee Arthroplasty: A Viable Surgical Option for Complex Tibial Plateau Fractures in Elderly. J Knee Surg. https://doi.org/10.1055/ s-0039-1679921

37. Kilian U (2003) Total knee replacement for primary treatment of intra-articular tibial head fractures in elderly patients. Unfallchirurg 106:1046-1050. https://doi.org/10.1007/s00113-003-0643-4

38. Kini SG, Sathappan SS (2013) Role of navigated total knee arthroplasty for acute tibial fractures in the elderly. Arch Orthop Trauma Surg 133:1149-1154. https://doi.org/10.1007/s00402-013-1792-8

39. Saleh KJ, Sherman P, Katkin P, et al (2001) Total knee arthroplasty after open reduction and internal fixation of fractures of the tibial plateau: a minimum five-year follow-up study. J Bone Joint Surg Am 83-A:1144-8

40. Lunebourg A, Parratte S, Gay A et al (2015) Lower function, quality of life, and survival rate after total knee arthroplasty for posttraumatic arthritis than for primary arthritis. Acta Orthop 86:189-194. https://doi.org/10.3109/17453674.2014.979723

41. Gaunder CL, Zhao Z, Henderson C et al (2018) Wound complications after open reduction and internal fixation of tibial plateau fractures in the elderly: a multicentre study. Int Orthop. https:// doi.org/10.1007/s00264-018-3940-9

42. Meulenkamp B, Martin R, Desy NM et al (2017) Incidence, Risk Factors, and Location of Articular Malreductions of the Tibial Plateau. J Orthop Trauma 31:146-150. https://doi.org/10.1097/ BOT.0000000000000735

43. Shao J, Chang H, Zhu Y et al (2017) Incidence and risk factors for surgical site infection after open reduction and internal fixation of tibial plateau fracture: A systematic review and meta-analysis. Int J Surg 41:176-182. https://doi.org/10.1016/j.ijsu.2017.03.085

44. Lin S, Mauffrey C, Hammerberg EM et al (2014) Surgical site infection after open reduction and internal fixation of tibial plateau fractures. Eur J Orthop Surg Traumatol 24:797-803. https://doi. org/10.1007/s00590-013-1252-8

45. Riou B, Rothmann C, Lecoules $\mathrm{N}$ et al (2007) Incidence and risk factors for venous thromboembolism in patients with nonsurgical isolated lower limb injuries. Am J Emerg Med 25:502-508. https://doi.org/10.1016/j.ajem.2006.09.012

46. Kubiak EN, Beebe MJ, North K et al (2013) Early Weight Bearing After Lower Extremity Fractures in Adults. J Am Acad Orthop Surg 21:727-738. https://doi.org/10.5435/JAAOS-21-12-727

47. Dittmer DK, Teasell R (1993) Complications of immobilization and bed rest. Part 1: Musculoskeletal and cardiovascular complications. Can Fam Physician 39:1428-32, 1435-7

48. Mehin R, O'Brien P, Broekhuyse H et al (2012) Endstage arthritis following tibia plateau fractures: average 10-year follow-up. Can J Surg 55:7-94. https://doi.org/10.1503/cjs.003111

49. Oladeji L, Dreger T, Pratte E et al (2018) Total Knee Arthroplasty versus Osteochondral Allograft: Prevalence and Risk Factors following Tibial Plateau Fractures. J Knee Surg. https://doi.org/10. 1055/s-0038-1641593

50. Tejwani NC, Hak DJ, Finkemeier CG, Wolinsky PR (2006) Highenergy proximal tibial fractures: treatment options and decision making. Instr Course Lect 55:367-379

51. Weiss NG, Parvizi J, Hanssen AD et al (2003) Total knee arthroplasty in post-traumatic arthrosis of the knee. J Arthroplasty 18:23-26. https://doi.org/10.1054/arth.2003.50068

52. Civinini R, Carulli C, Matassi F et al (2009) Total knee arthroplasty after complex tibial plateau fractures. Musculoskelet Surg 93:143-147. https://doi.org/10.1007/s12306-009-0033-3

53. Bala A, Penrose CT, Seyler TM et al (2015) Outcomes after Total Knee Arthroplasty for post-traumatic arthritis. Knee 22:630-639. https://doi.org/10.1016/j.knee.2015.10.004

54. El-Galaly A, Haldrup S, Pedersen AB et al (2017) Increased risk of early and medium-term revision after post-fracture total knee arthroplasty: Results from the Danish Knee Arthroplasty Register. Acta Orthop 88:263-268. https://doi.org/10.1080/17453674.2017. 1290479

55. Houdek MT, Watts CD, Shannon SF et al (2016) Posttraumatic Total Knee Arthroplasty Continues to Have Worse Outcome Than Total Knee Arthroplasty for Osteoarthritis. J Arthroplasty 31:118-123. https://doi.org/10.1016/j.arth.2015.07.022

56. Scharf S, CHRISTOPHIDIS N, (1994) Fractures of the tibial plateau in the elderly as a cause of immobility. Aust N Z J Med 24:725-726. https://doi.org/10.1111/j.1445-5994.1994.tb01792.x

Publisher's Note Springer Nature remains neutral with regard to jurisdictional claims in published maps and institutional affiliations. 